\title{
A System for Track Sun Trajectory for Increasing Efficiency of Solar Panel Module using Camera
}

\author{
Nitin Mishra, Shrikant Vaishnav, Nandlal Shah
}

\begin{abstract}
The Solar power is the future of mankind because is availability on earth and with very less carbon footprint. The solar power in upcoming years will dominant the power generation industry and will improve the climatic conditions of planet earth. The solar panel efficiency is improving as technology is improving. There are many techniques are used for improving the power output from solar panel module like temperature reduction and solar tracking. In solar tracking technique the position of sun is tracked by using different techniques. In this paper we will discuss about the Camera based solar tracking system.
\end{abstract}

Keywords: Solar power, Solar panel, Camera, Solar tracking, Efficiency.

\section{INTRODUCTION}

The solar electrical power system is fastest growing renewable energy system. The total solar energy output of world is 405 gigawatt out of which $89 \%$ is installed in last decade and growing[1]. As technology advances the cost of generation is decreasing and efficiency of solar panel module is increasing as time passes. There are several methods for increasing the efficiency of solar panel module like solar tracking, temperature reduction of solar panel and many more[2]. The solar tracking is a technique in which by using different sensor the position of sun is determined and solar panel module is aligned accordingly, thus increasing the total output of system. The solar tracking is of two type one is single axis and second is dual axis solar tracking. In dual axis solar tracking sun is tracked horizontally and vertically by using a particular system[3]

\section{METHODOLOGY USED:}

The model is constructed using a 20 watt solar panel module, which is fixed on a platform capable of moving horizontally and vertically by the help of two fixed servo motors controlled by Arduino Uno. The Arduino Uno acts as a gateway between a main processing unit i.e. a computer. The Arduino Uno receives the feedback from main processing unit and rotates the motor and align the solar panel module accordingly. The main processing unit processes the image taken from camera and performs all the calculation by it-self.

Revised Manuscript Received on September 14, 2019.

Nitin Mishra, Department of Electrical \& Electronics Engineering, Rabindranath Tagore University, Bhopal, Madhya Pradesh, India.

Shrikant Vaishnav, Department of Electrical \& Electronics Engineering, Rabindranath Tagore University, Bhopal, Madhya Pradesh, India.

Nandlal Shah, Department of Electrical \& Electronics Engineering, Rabindranath Tagore University, Bhopal, Madhya Pradesh, India.

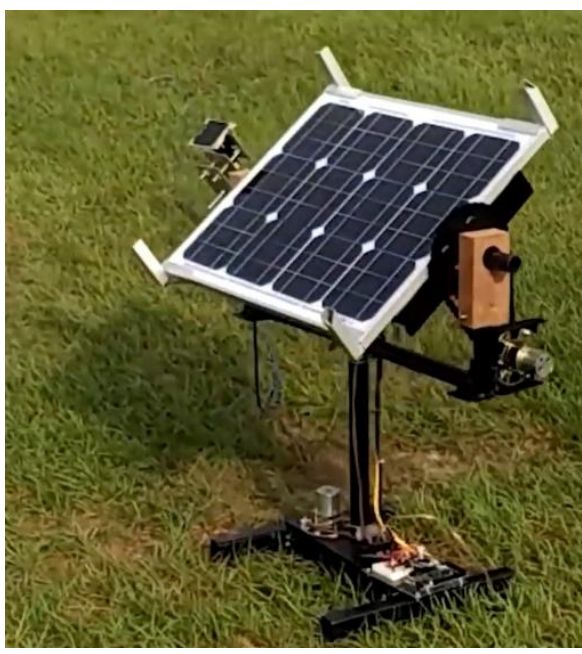

Figure 1: Model

As shown in figure 1, the camera is covered by a welding glass for saving camera from harsh sun light and for taking more clear photos of sun, the welding glass act as filter for camera for generating more clear images of sun.

\section{WORKING OF SYSTEM:}

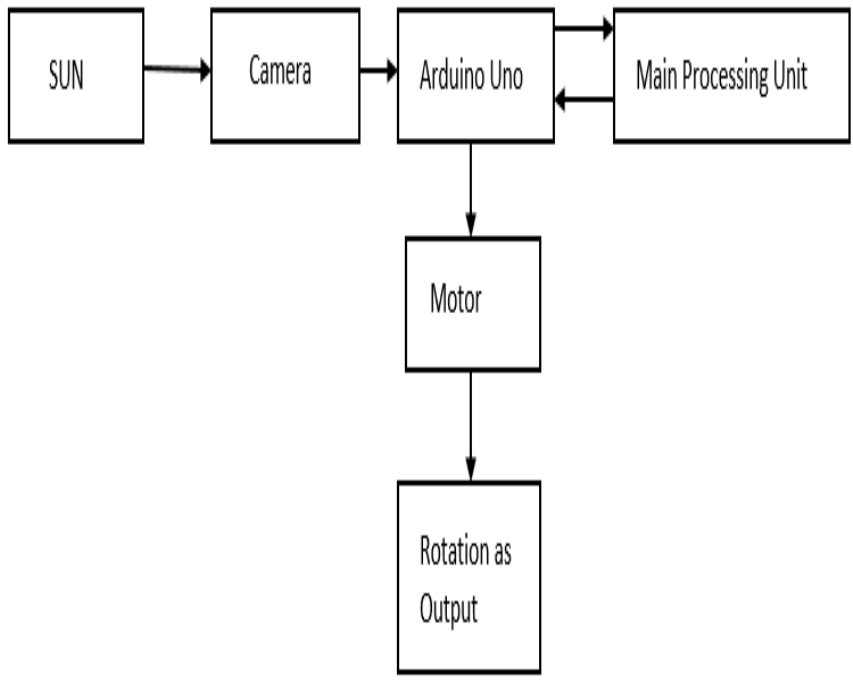

Figure 2: Block Diagram of System

The camera captures the images of sun at 50 FPS and send the taken images of the Arduino Uno. The Arduino Uno acts as bridge between processing unit and functional unit, the captured images than sent to main processing unit. In main processing unit the images is processed and

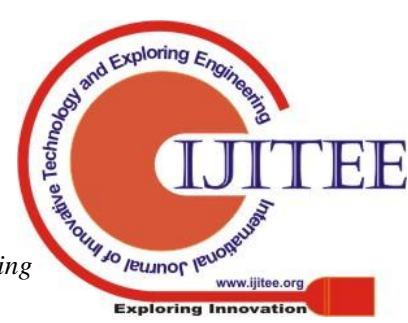


converted into main different type for making process fast and more accurate. First the images is captured in RGB format, The RGB image than converted into 'value' plane than to Binarized, After that binarized image is converted into Erode format afterwards to Contour and in last we get resulting image which is show the actual image of sun and its location to processing unit[4].

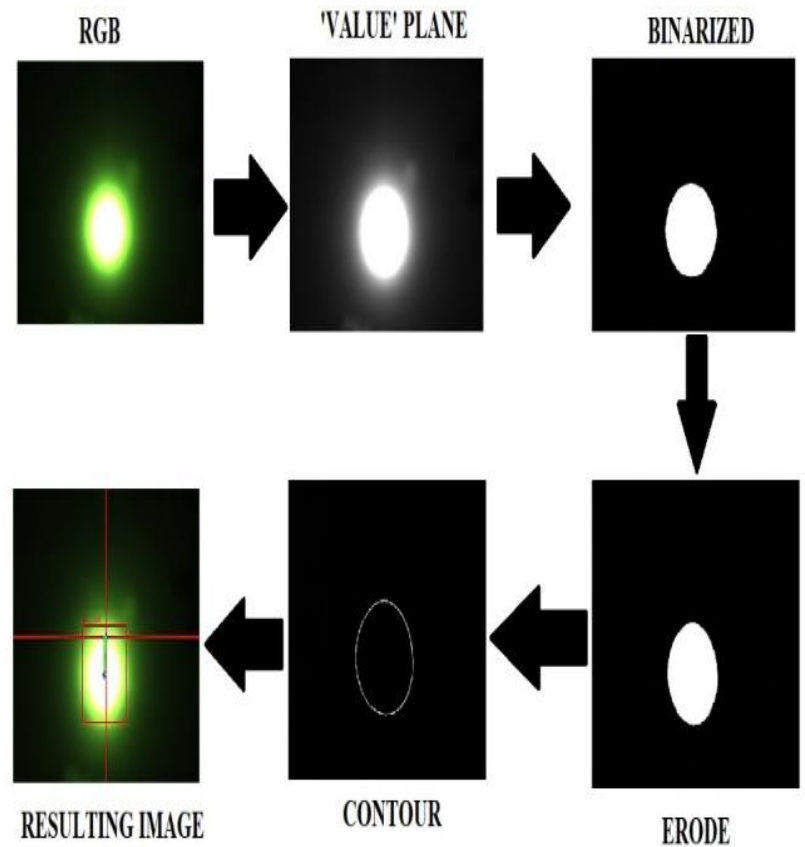

Figure 3: Image Conversion by main processing unit

The data processed by main processing unit is transferred to Arduino Uno regarding the location of sun and how much the system should adjust for getting maximum power from sun. The Arduino Uno than controls the servo motor and adjust the system position

\section{COMPONENTS USED IN SYSTEM:}

\section{Camera:}

The camera module OV7670 is used in the system for capturing the images of and sent to Arduino Uno. The camera module is directly connected with Arduino Uno[5].

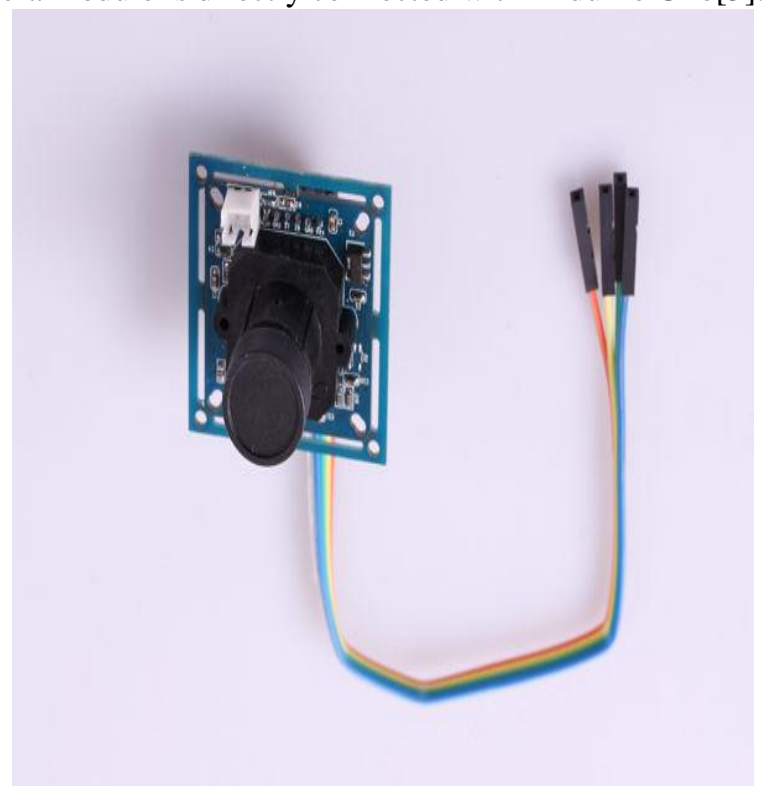

Figure 4: Camera module CV 7670

\section{Arduino Uno:}

The Arduino Uno act as bridge between main processing unit, functional unit and input unit of system. Arduino Uno receives the captured images form camera and send the captured images to main processing unit for processing. The IC used in Arduino Uno is Atmega628[6] for processing unit and Arduino Uno receives data from main processing unit regarding the location of sun and data related to adjustment in solar panel module for harnessing maximum power through solar panel module by using servo motor.

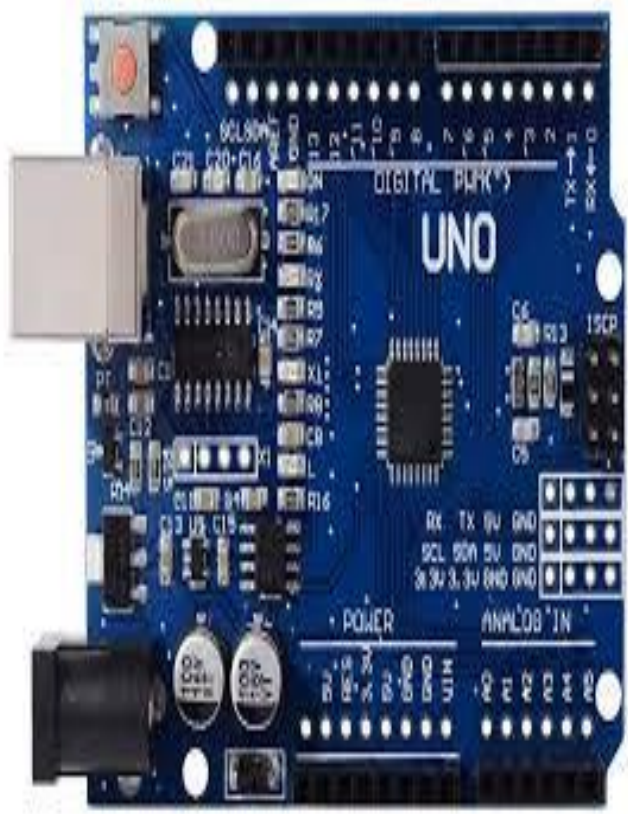

Figure 5: Arduino Uno

Servo Motor:

The servo motor is used for adjusting the solar panel module. The servo motors degree of rotation or angel of rotation is easily controlled by using micro controlled. The servo motor also provide high torque by using a set of gear for providing high torque[7].

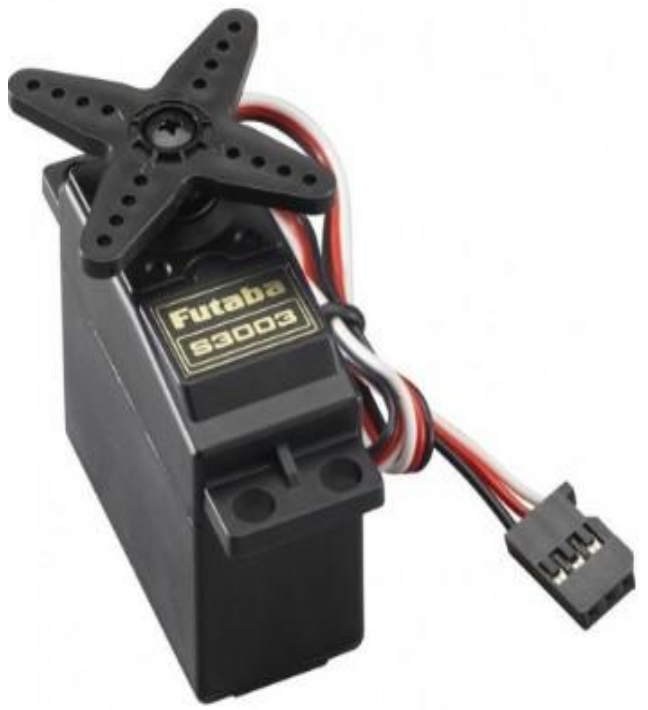

Figure 6: Servo Motor

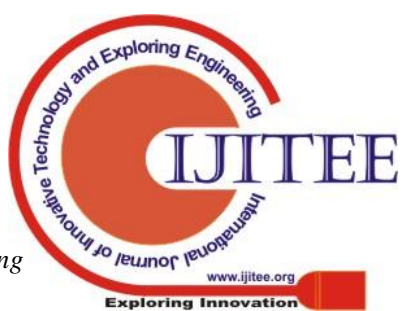




\section{CONVENTIONAL SYSTEM VS CAMERA BASED SOLAR TRACKING \& RESULTS:}

CAMERA BASED
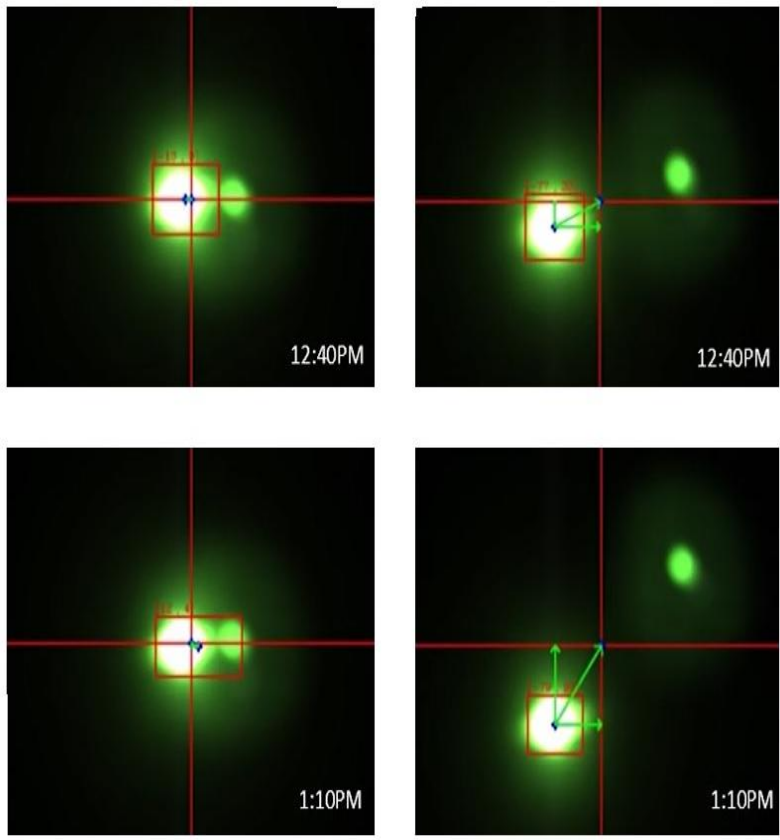

Figure 7: Camera based vs LDR based System

According to figure 7 camera based solar tracking system is more accurate as compare to Light Detecting Resistor (LDR) based solar tracking system. Due to in Camera based system we use image processing and get more accurate results and because of these results the adjustments are made more accurate.

\section{CONCLUSION:}

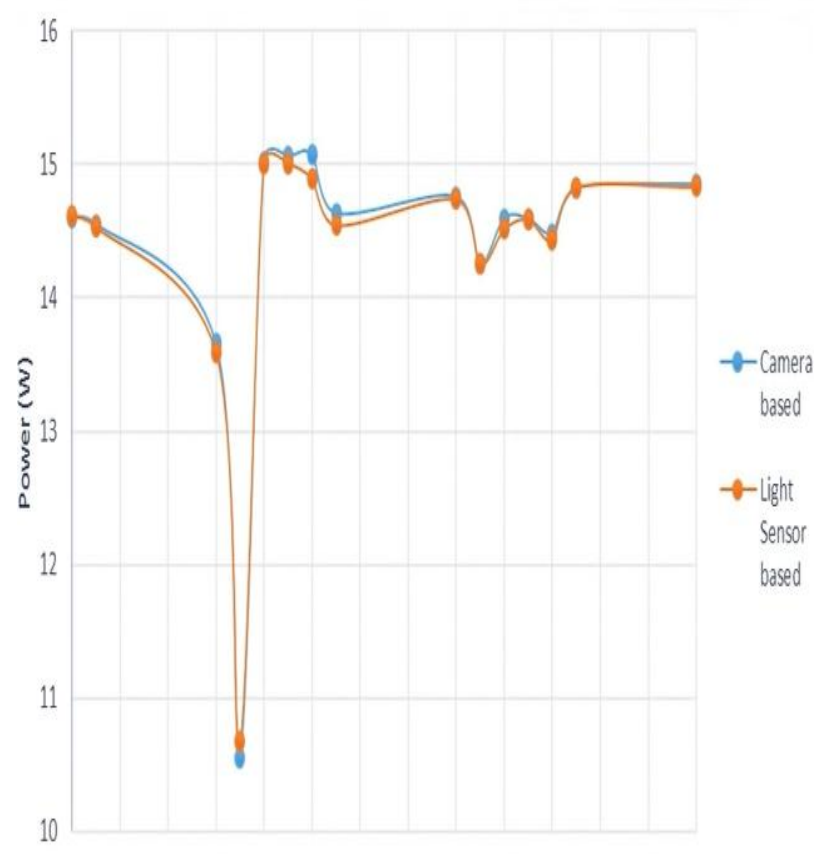

11401160118012001220124012601280130013201340136013801400

Time

Graph 1: Camera based system power output vs LDR based system power output
According to graph 1 the power output of Camera based system is more than light sensor based system on an average. By using Camera Based system the efficiency of system is increased by $0.165 \%$ as compare to LDR based system.

The system can also stores the weather related data, generated from images like the weather is cloudy, sunny, windy or partially cloudy as shown in below image.
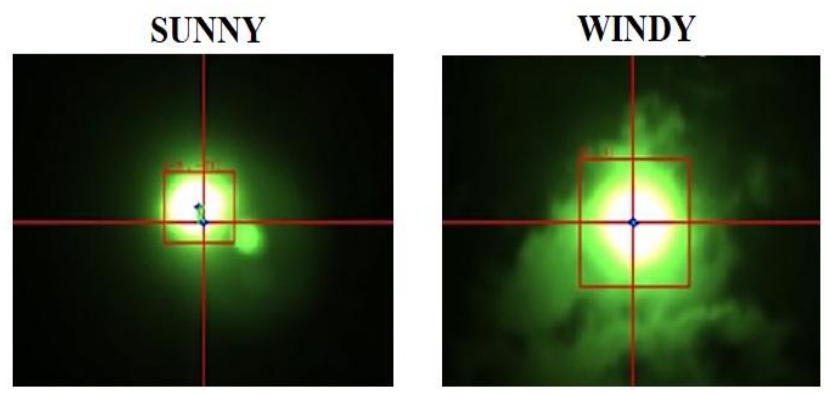

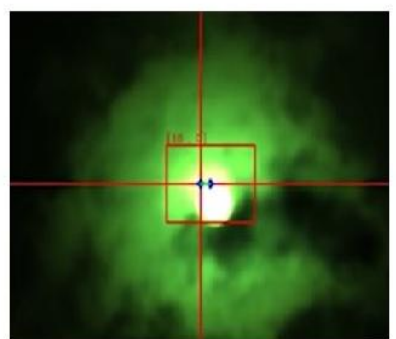

PARTIALLY CLOUDY

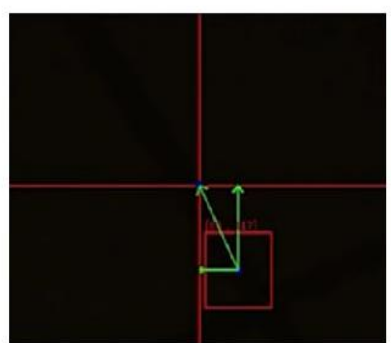

CLOUDY
Figure 8: Weather detection by Camera based system.

\section{REFERENCES}

1. G. K. Singh, "Solar power generation by PV (photovoltaic) technology: A review," Energy. 2013.

2. V. Sumathi, R. Jayapragash, A. Bakshi, and P. Kumar Akella, "Solar tracking methods to maximize PV system output - A review of the methods adopted in recent decade," Renewable and Sustainable Energy Reviews. 2017.

3. A. Z. Hafez, A. M. Yousef, and N. M. Harag, "Solar tracking systems: Technologies and trackers drive types - A review," Renewable and Sustainable Energy Reviews. 2018

4. E. A. B. da Silva and G. V. Mendonca, "Digital Image Processing," in The Electrical Engineering Handbook, 2005.

5. D. Patel, R. Parmar, A. Desai, and S. Sheth, "Gesture recognition using FPGA and OV7670 camera," in Proceedings of the International Conference on Inventive Systems and Control, ICISC 2017, 2017.

6. D. R. Tobergte and S. Curtis, "Arduino Uno," J. Chem. Inf. Model., 2013.

7. top-eng, "Servo Motor," top engineer, 2013 